\title{
VAlidasi Model TURbulensi Pada Simulasi NumeriK MENGGUNAKAN SOFTWARE FLUENT DENGAN SAYAP ONERA M6
}

\section{VALIDATION OF TURBULENCE MODEL IN NUMERICAL Simulation Using Fluent SofTWARE With Wings ONERA M6}

\author{
Sulistiya ${ }^{1}$, Alief Sadlie K. ${ }^{1}$ \\ ${ }^{1}$ Balai Besar Teknologi Aerodinamika, Aeroelastika dan Aeroakustika - BPPT \\ Kawasan PUSPIPTEK Gedung 240, Setu, Tangerang Selatan - Banten, Indonesia
}

\begin{abstract}
Abstraks
Simulasi numerik dengan menggunakan metode Computational Fluid Dynamics (CFD) merupakan salah satu cara untuk memprediksi karakteristik suatu aliran udara yang terjadi pada model. Metode ini banyak digunakan karena sifatnya yang relatif murah dan cepat untuk mendapatkan hasil dibandingkan dengan melakukan pengujian langsung. Benar tidak hasil sebuah simulasi komputasi sangat tergantung pada inputan yang diberikan serta cara memproses data inputan tersebut. Pada tulisan ini dilakukan simulasi dengan menggunakan sayap onera M6 dengan tujuan untuk mengetahui pengaruh penggunaan model turbulensi terhadap keakuratan hasil komputasi. Pilihan sayap onera M6 sebagai model simulasi dikarenakan model tersebut sudah memiliki database hasil pengujian yang cukup lengkap dan sudah divalidasi dari berbagai terowongan angin di dunia. Model turbulensi yang digunakan diantaranya Spalart-Allmaras, K-Epsilon, K-Omega dan SST.
\end{abstract}

Kata Kunci : CFD, fluent, Model, Turbulensi, Onera M6, Spalart-Allmaras, K-Epsilon, K-Omega, SST.

\begin{abstract}
Numerical simulation using Computational Fluid Dynamics (CFD) method is one way of predicting airflow characteristics on the model. This method is widely used because it is relatively inexpensive and faster in getting desired results compared with performing direct testing. The correctness of a computational simulation output is highly dependent on the input and how it was processed. In this paper, simulation is done on Onera M6 Wing, to investigate the effect of a turbulence model's application on the accuracy of the computational result. The choice of Onera M6 Wing as a simulation's model is due to its extensive database of testing results from various wind tunnels in the world. Among Turbulence models used are Spalart-Allmaras, K-Epsilon, K-Omega, and SST.
\end{abstract}

Keywords: CFD, fluent, Model, Turbulence, Onera M6, Spalart-Allmaras, K-Epsilon, K-Omega, SST.

\section{Pendahuluan}

Computational Fluid Dynamics (CFD) merupakan suatu metode komputasi numerik untuk menyelesaikan persamaan aliran suatu benda dalam aliran fluida dengan berbasis komputer [1]. CFD dapat mengsimulasikan aliran udara, perpindahan panas, perpindahan massa, benda bergerak, reaksi kimia dengan membuat pemodelan di komputer. Salah satu software CFD yang sering digunakan untuk mensimulasikan aliran adalah Fluent [2]. Dalam Fluent pemilihan model turbulensi sangat menentukan keakuratan hasil simulasi. Secara garis besar, model turbulensi digunakan untuk memodifisikan persamaan Navier Stokes sebagai pendekatan sistem aliran utama dengan memperkenalkan kuantitas ratarata dan besar fluktuasi untuk menghasikan persamaan Reynold Average Navier Stokes (RANS) sehingga

* Sulistiya. Tel: +62 217560902 masalah aliran yang bervariasi dapat dihitung [3].

E-mail: sulistiya@bppt.go.id 
Hasil experiment Sayap Onera M6 [4] merupakan salah satu tipe sayap yang banyak digunakan untuk melakukan validasi CFD. Pada makalah ini akan membahas pengaruh penggunaan model turbulensi terhadap keakuratan hasil komputasi di fluent pada simulasi numerik sayap onera m6. Hasil komputasi berupa distribusi keofisien tekanan $(\mathrm{CP})$ di sekitar permukaan sayap yang akan dibandingkan dengan hasil eksperimen.

\section{DASAR TeOrI}

Persamaan Navier-stokes merupakan sistem persamaan differensial non-linier yang mendeskripsikan bagaimana fluida mengalir [1]. Persamaan ini menjelaskan keseimbangan gaya-gaya yang bekerja pada fluida yaitu gaya-gaya benda dan gaya-gaya permukaan. Dalam menentukan solusi persamaan numerik, model turbulensi adalah prosedur komputasional untuk mendekatkan sistem persamaan aliran sehingga masalah aliran yang bervariasi dapat dihitung. Secara garis besar, model turbulensi digunakan untuk memodifikasi persamaan Navier Stokes dengan memperkenalkan kuantitas rata-rata dan besar fluktuasi untuk menghasilkan persamaan Reynolds Averaged Navier Stokes. Dalam persamaan CFD persamaan RANS dirumuskan [5].

$$
\begin{gathered}
\frac{\partial \rho}{\partial t}+\frac{\partial}{\partial x_{i}}\left(\rho u_{i}\right)=0 \\
\frac{\partial}{\partial t}\left(\rho u_{i}\right)+\frac{\partial}{\partial x_{j}}\left(\rho u_{i} u_{j}\right)=-\frac{\partial p}{\partial x_{i}}+\frac{\partial}{\partial x_{j}}\left[\mu\left(\frac{\partial u_{i}}{\partial x_{j}}+\frac{\partial u_{j}}{\partial x_{i}}-\frac{2}{3} \delta \frac{\partial u_{l}}{\partial x_{l}}\right)\right]+\frac{\partial}{\partial x_{j}}\left(-\rho \overline{\dot{u}_{i} \dot{u}_{j}}\right)
\end{gathered}
$$

Model turbulensi yang sering digunakan untuk memodifikasikan persamaan RANS diantaranya Spalart-Almarast, k-epsilon, k-omega dan shear stess transport (SST).

\section{A. Spalart-Allmaras}

Spalart-Allmaras merupakan model turbulensi dengan satu persamaan yang menyelesaikan model persamaan transport untuk viskositas kinematik turbulen. Model ini dapat digunakan untuk simulasi yang relatif kasar dengan ukuran mesh yang besar dimana perhitungan aliran turbulen bukan merupakan hal yang bersifat kritis. Pemodelan yang akurat di dekat dinding merupakan hal yang penting untuk kebanyakan aplikasi teknik karena perkiraan penurunan tekanan (pressure drop), separasi aliran, lapisan batas bergantung kepada kebenaran prediksi gaya geser lokal pada dinding tersebut. Oleh karena itu diperlukan treatment tambahan untuk membuat kedua model tersebut lebih akurat untuk memprediksikan perilaku aliran di dekat dinding, terutama pada aliran yang sangat terpengaruh oleh dinding (wall-bonded flow) [3]. Persamaan transport untuk model turbulensi Spalart-Almarast (SA) dinyatan sebagai berikut [6].

$$
\frac{\partial}{\partial t}(\rho \tilde{v})+\frac{\partial}{\partial x_{i}}\left(\rho \tilde{v} u_{i}\right)=G_{v}+\frac{1}{\sigma_{\tilde{v}}}\left[\frac{\partial}{\partial x_{j}}\left\{(\mu+\rho \tilde{v}) \frac{\partial \widetilde{v}}{\partial x_{j}}\right\}+C_{b 2} \rho\left(\frac{\partial \widetilde{v}}{\partial x_{j}}\right)^{2}\right]-Y_{v}+S_{\tilde{v}}
$$

dimana $G_{\mathrm{v}}$ adalah viskositas turbulen produksi, $Y_{v}$ adalah viskositas turbulen destruksi pada daerah dekat dinding karena adanya dinding penghalang dan redaman viskos, $v$ adalah viskositas kinematic

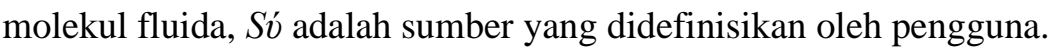

\section{B. K-Epsilon}

Mmodel ini merupakan model semi empiris yang dikembangkan oleh Launder \& Spalding. Model $k$ epsilon merupakan model turbulensi yang cukup lengkap dengan dua persamaan yang memungkinkan kecepatan turbulen (turbulent velocity) dan skala panjang (length scales) ditentukan secara independen. Kesetabilan, ekonomis (dari sisi komputasi) dan akurasi yang memadai untuk berbagai jenis aliran turbulen membuat model k-epsilon sering diguakan pada simulasi fluida dan perpindahan panas [3].

Model k-epsilon standar didasarkan pada persamaan transport untuk enegi kinetic turbulen $(k)$ dan tingkat disipasinya $(\varepsilon)$. Energi kinetic turbulen dan laju disipasinya dapat diperoleh dari dua persamaan transport berikut [5]: 


$$
\begin{gathered}
\frac{\partial}{\partial t}(\rho k)+\frac{\partial}{\partial x_{i}}\left(\rho k u_{i}\right)=\frac{\partial}{\partial x_{j}}\left[\left(\mu+\frac{\mu_{t}}{\sigma_{k}}\right) \frac{\partial k}{\partial x_{j}}\right]+G_{k}+G_{b}-\rho \varepsilon-Y_{M}+S_{k} \\
\frac{\partial}{\partial t}(\rho \varepsilon)+\frac{\partial}{\partial x_{i}}\left(\rho \varepsilon u_{i}\right)=\frac{\partial}{\partial x_{j}}\left[\left(\mu+\frac{\mu_{t}}{\sigma_{\varepsilon}}\right) \frac{\partial \varepsilon}{\partial x_{j}}\right]+C_{1 \varepsilon} \frac{\varepsilon}{k}\left(G_{k}+C_{3 \varepsilon} G_{b}\right)-C_{2 \varepsilon} \rho \frac{\varepsilon^{2}}{k}+S_{\varepsilon}
\end{gathered}
$$

dimana $G_{k}$ merepresentasikan energi kinetik turbulensi dari gradient kecepatan rata-rata, $G_{b}$ merepresentasikan enerki kinetic turbulensi dari daya apung, $Y_{M}$ merepresentasikan kontribusi dari fluktuasi dilatasi pada aliran turbulen kompresibel terhadap keseluruhan tingkat disipasi. $C_{I \varepsilon}, C_{2 \varepsilon}$ dan $C_{3 \varepsilon}$ adalah konstanta. $\sigma_{k}$ dan $\sigma_{\varepsilon}$ adalah turbulent Pradl number untuk masing-masing $k$ dan $\varepsilon . S_{k}$ dan $S_{\varepsilon}$ adalah sumber yang ditentukan oleh pengguna.

\section{Model $k$-omega}

Model k-omega standar merupakan model turbulensi berdasarkan model Wilcox k-omega yang memasukkan beberapa modifikasi untuk menghitung efek aliran pada bilagan Reynolds rendah, kompresibilitas dan enyebaran aliran geser (shear flow). Model ini dapat diaplikasikan pada aliran dalam saluran maupun aliran bebas geseran (free shear flow) [3]. Model k-omega standar didasarkan model empiris berdasarkan model persamaan transport untuk energy kinetik turbulen $\mathrm{k}$ dan tingkat disipasi spesifik $\omega$, atau disebut juga rasio antara $\varepsilon$ terhadap $k$. pada model ini, istilah produksi telah ditambahkan dalam persamaan untuk meningkatkan akurasi prediksi penyebaran aliran geser [5].

$$
\begin{aligned}
& \frac{\partial}{\partial t}(\rho k)+\frac{\partial}{\partial x_{i}}\left(\rho k u_{i}\right)=\frac{\partial}{\partial x_{j}}\left(\Gamma_{k} \frac{\partial k}{\partial x_{j}}\right)+G_{k}-Y_{k}+S_{k} \\
& \frac{\partial}{\partial t}(\rho \omega)+\frac{\partial}{\partial x_{i}}\left(\rho \omega u_{i}\right)=\frac{\partial}{\partial x_{j}}\left(\Gamma_{\omega} \frac{\partial \omega}{\partial x_{j}}\right)+G_{\omega}-Y_{\omega}+S_{\omega}
\end{aligned}
$$

dimana $G_{k}$ merepresentasikan energi kinetik turbulensi dari gradient kecepatan rata-rata, $G_{\omega}$ merepresentasikan tingkat disipasi energi $\omega, \Gamma \mathrm{k}$ dan $\Gamma \omega$ merepresantasikan difusivitas efektif dari $k$ dan $\omega, Y_{k}$ dan $Y_{\omega}$ merepresentasikan disipasi turbulensi dari $k$ dan $\omega . S_{k}$ dan $S_{\omega}$ adalah sumber yang ditentukan oleh pengguna.

\section{Model Shear Stress Transport}

Salah satu pemasalahan utama dalam memodelkan turbulensi adalah perdiksi yang akurat terhadap separasi aliran di permukaan yang halus. Model turbulen 2-equation sering gagal dalam dalam memprediksi letak awal dan jumlah separasi aliran didalam kondisi adverse pressure gradient. Hal ini adalah fenomena yang penting dalam berbagai aplikasi teknis khususnya aerodinamika pesawat karena karakteristik stallnya diatur oleh separasi aliran pada sayap. Oleh karena itu dikembangkan model yang dapat memprediksi separasi aliran dengan lebih akurat.

Model Shear-Stress-Transport (SST) didesain untuk memberikan akurasi yang tinggi terhadap letak awal dan jumlah aliran dalam separasi didalam adverse pressure gradient dengan memasukkan efek transport ke dalam formulasi eddy viscosity. Model ini disarankan untuk simulasi lapisan batas yang akurat. Oleh karena itu dibutuhkan resolusi yang tinggi pada lapisan batas. Model SST memiliki kelebihan dapat memprediksi separasi aliran dengan lebih akurat Sangat cocok untuk mendapatkan akurasi tinggi di lapisan batas, akurasi dalam menangani komputasi near wall treatment pada bilangan

Reynolds rendah. Selain kelebihan model SST juga mempunyai kekurangan yaitu dibutuhkan grid yang bagus dan rapat di sekitar wall yang berarti dibutuhkan usaha lebih besar pada saat grid generation.

Persamaan transport untuk model turbulensi SST didefinisikan sebagai berikut [5]:

$$
\frac{\partial(\rho \gamma)}{\partial t}+\frac{\partial\left(\rho U_{j \gamma}\right)}{\partial x_{j}}=P_{\gamma 1}-E_{\gamma 1}+P_{\gamma 2}-E_{\gamma 2}+\frac{\partial}{\partial x_{j}}\left[\left(\mu+\frac{\mu_{t}}{\sigma_{\gamma}}\right) \frac{\partial \gamma}{\partial x_{j}}\right]
$$

dimana adalah $\gamma$ intermitensi, $P_{\gamma 1}$ dan $E_{\gamma 1}$ adalah sumber transisi, $P_{\gamma 2}$ dan $E_{\gamma 2}$ adalah sumber destruksi/relaminasi.

\section{Metodologi Komputasi}


A. Geometri, Mesh dan Kondisi Batas

Geometri yang dimodelkan dalam simulasi ini adalah geometri sayap yang diambil dari model sayap m6 Onera yang memiliki panjang span 1.1963 m dan Mean Aerodynamic Chord (MAC) 0.64607 m. Dari permukaan saya dibuat 7 irisan untuk mengetahui ditribusi koefisien tekanan disekitar permukaan irisan tersebut. Bentuk dan deskripsi geometri sayap M6 Onera secara rinci dapat dilihat pada gambar 1 dan tabel 1 [4].

\begin{tabular}{|c|c|}
\hline \multicolumn{2}{|c|}{ Tabel 1. Deskripsi geometri sayap M6 Onera } \\
\hline Span, b & 1.1963 meters \\
\hline Mean Aerodynamic Chord, c & 0.64607 meters \\
\hline Aspect Ratio & 3.8 \\
\hline Taper Ratio & 0.562 \\
\hline Leading-edge Sweep & 30.0 degrees \\
\hline Trailing-edge Sweep & 15.8 degrees \\
\hline
\end{tabular}

Domain komputasi berbentuk balok dengan panjang domain 31 kali, lebar domain 10 kali dan tinggi domain 20 kali panjang root chord sayap. Kondisi batas simulasi yang digunakan pada simulasi ini adalah pressure farfield, symmetry dan wall. Kondisi batas pressure farfield digunakan untuk bagian inlet, bagian atas, bagian bawah dan bagian samping kanan sayap yang mengambil jarak 10 kali panjang root chord sayap, serta bagian outlet yang mengambil jarak 20 kali panjang root chord sayap [7].

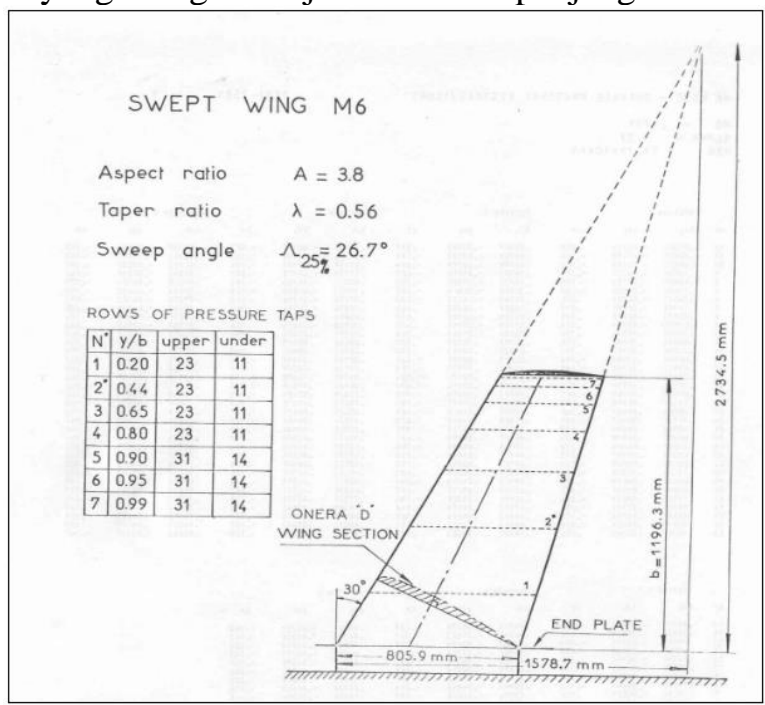

Gambar 1. Geometri sayap M6 Onera. [8]

Kondisi batas symmetry digunakan pada bagian kiri domain yang merupakan bidang simetri dari sayap. Sedangkan kondisi batas wall digunakan untuk memodelkan bagian permukaan sayap. Domain dan kondisi batas simulasi dapat dilihat pada gambar 2 di bawah ini 


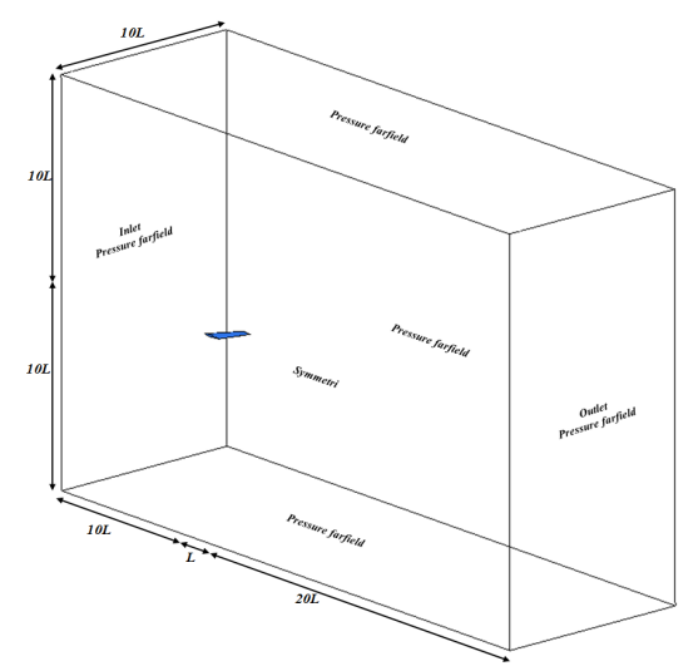

Gambar 2. Domain dan kondisi batas simulasi

Mesh dibuat menggunakan perangkat lunak dengan metode automesh sehingga lebih cepat waktu yang dibutuhkan untuk membentuk suatu mesh. Bentuk mesh pada simulasi ini adalah perpaduan hexahedral unstructured yang menyesuaikan bentuk geometri ssayap. Jumlah grid yang dihasilkan berjumlah 3145835 sel dengan tebal lapisan batas pertama yang menempel pada dinding adalah $2.45 \times 10^{-6} \mathrm{~m}$. Lapisan batas dekat dinding berjumlah 15 lapis dengan rasio tebal lapisan selanjutnya 1.3. Gambar mesh dipermukaan sayap ditunjukkan oleh gambar 3 dibawah ini.

\section{B. Skema Komputasi}

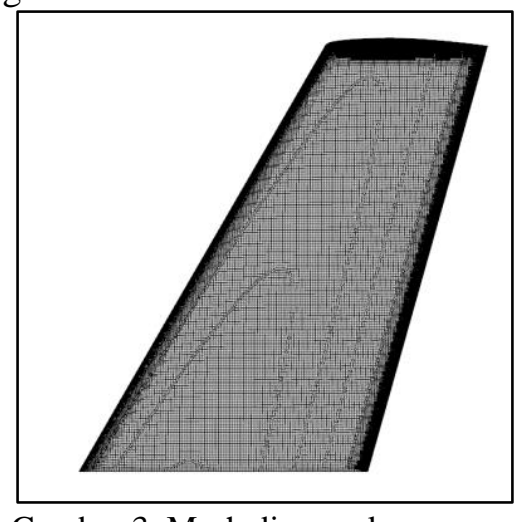

Persamaan atur yang digunakan dalam simulasi aliran fluida ini adalah persamaan Navier Stokes. Persamaan ini telah memasukan efek viskositas yang memungkinkan besarnya gaya-gaya seperti misalnya tahanan friksi dan tahanan tekanan dapat diprediksi dengan cukup akurat [3]. Kondisi pemodelan aliran simulasi CFD ditunjukkan pada table 2. Bilangan reynold yang digunakan adalah 11.72 juta berdasarkan panjang Mean Aerodynamic Chord (MAC) yaitu $0.64607 \mathrm{~m}$.

\begin{tabular}{|c|c|c|c|}
\hline \multicolumn{4}{|c|}{ Table 2. Kondisi aliran simulasi } \\
\hline Mach & Reynolds Number & Angle-of-Attack (deg) & Angle-of-Sideslip (deg) \\
\hline 0.8395 & $11.72 \mathrm{E}+06$ & 3.06 & 0.0 \\
\hline
\end{tabular}

\section{Pembahasan}

\section{A. Kontur $\mathbf{Y}^{+}$}

Gambar 4 sebelah kiri menunjukkan mesh pada sumbu simetri dengan permukaan M6-Wing yang diwarnai dengan kontur koefisien tekanan. Terlihat bahwa pada bagian trailing edge sampai bagian tip sayap memiliki koefisien tekanan yang seragam, sedangkan pada bagian atas leading edge memiliki koefisien tekanan yang rendah. Gambar 4 sebelah kiri menunjukkan kontur $\mathrm{Y}^{+}$dipermukaan sayap, 
terrlihat bahwa hampir seluruh permukaan sayap memiliki kontur $\mathrm{Y}^{+}$kurang dari 1 , hanya sebagian kecil saja yang memiliki nilai lebih dari 1 yaitu pada daerah di sisi-sisi ujung sayap [9].

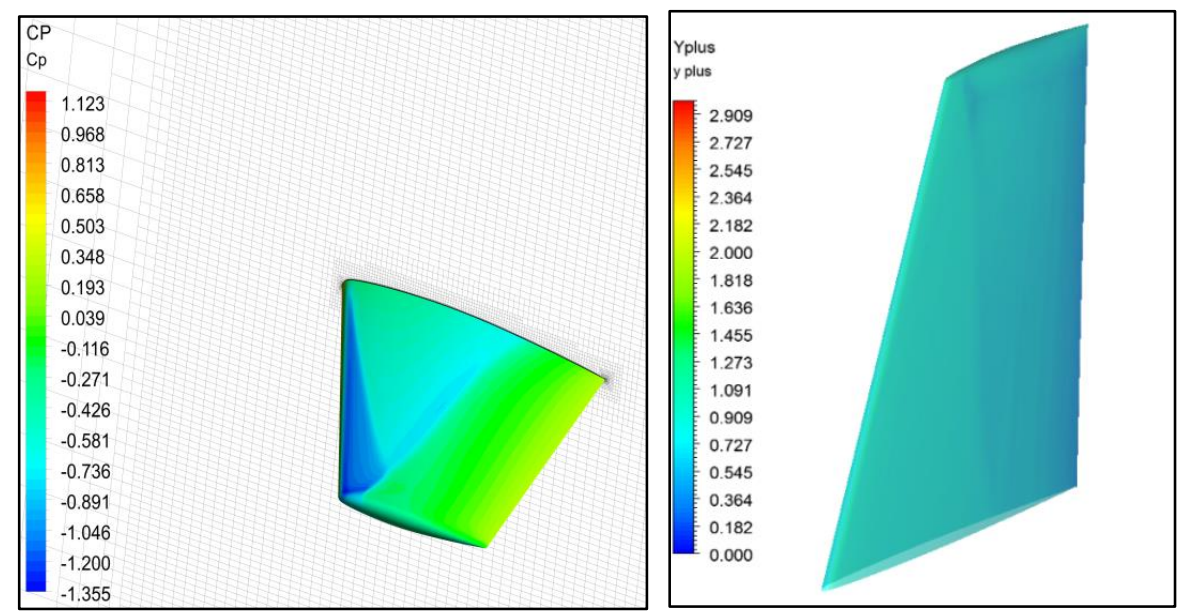

Gambar 4. Mesh dipermukaan sayap.

\section{B. Koefisien Tekanan Statik}

Koefisien tekanan statik hasil simulasi komputasi CFD M6 Wing Onera ditampil dalam bentuk grafik sekaligus dibandingkan dengan data experiment. Data dibagi berdasarkan pada posisi pressure taps experiment yang sudah dilakukan.

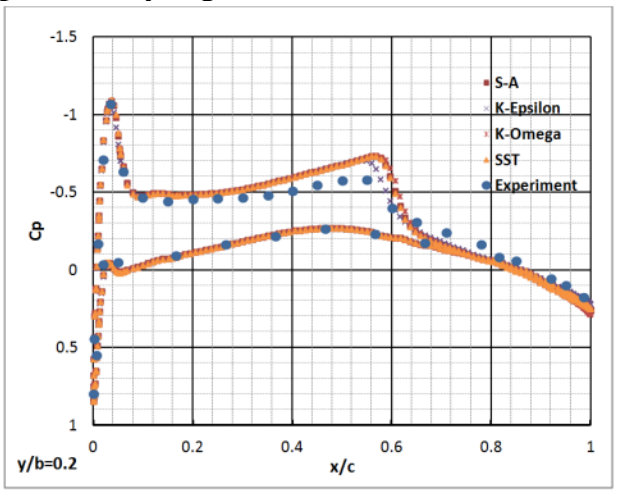

(a)

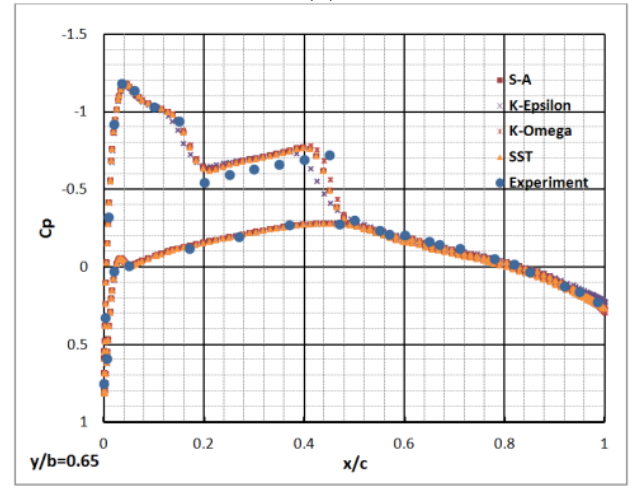

(c)

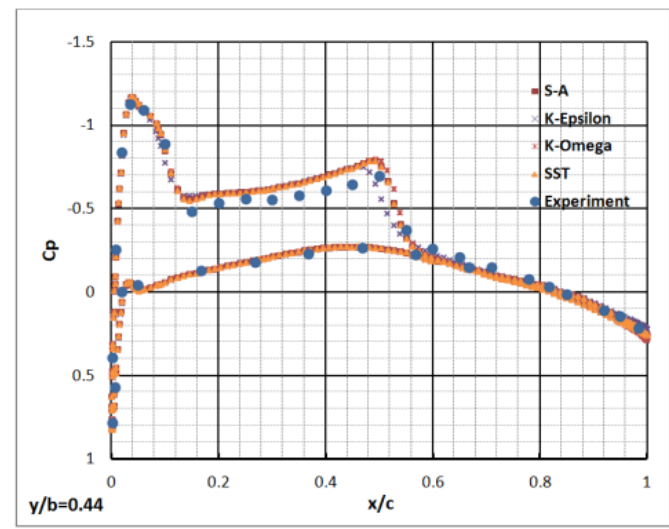

(b)

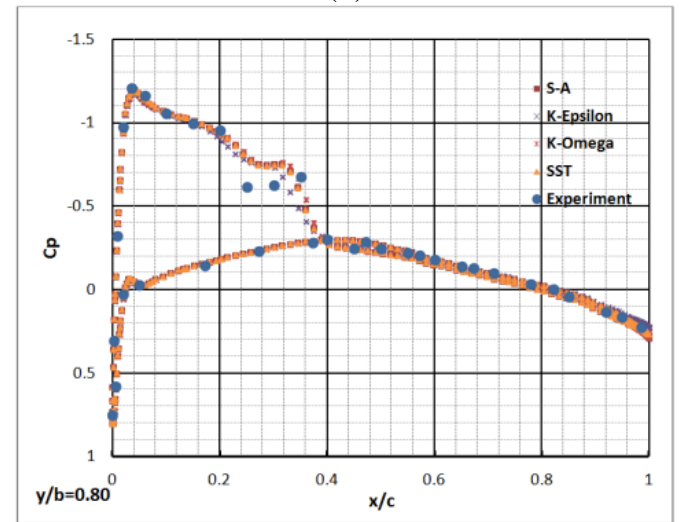

(d) 


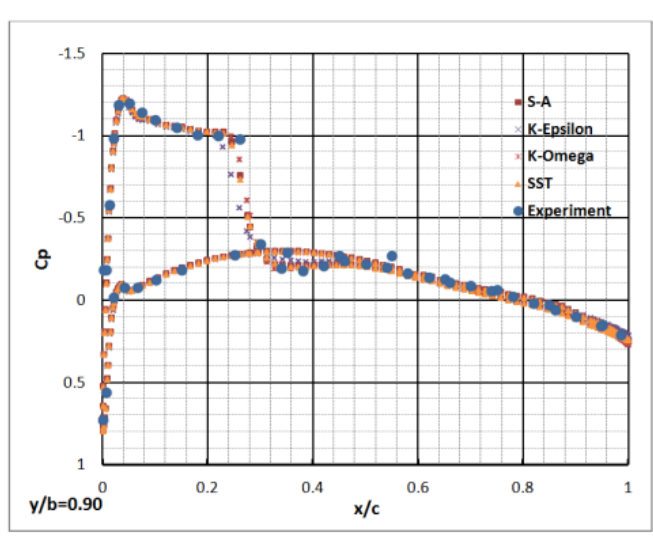

(e)

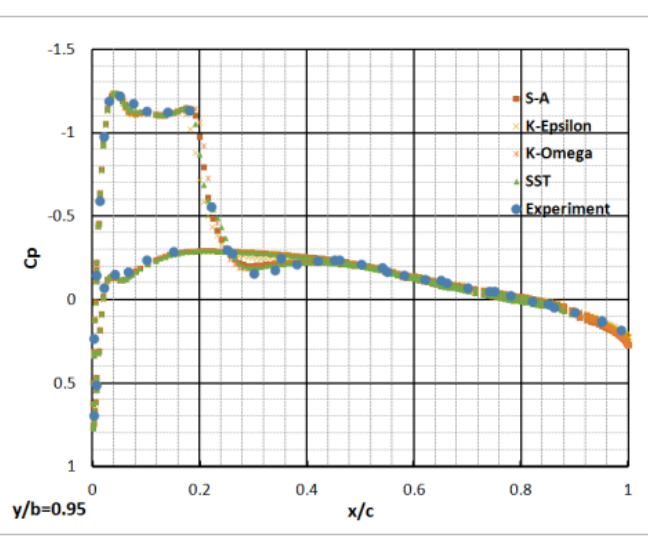

(f)

Gambar 5. Grafik koefisien tekanan statik pada setiap posisi pressure tap y/b

Data grafik koefisien tekanan statik yang ada dalam gambar 5 menunjukkan hasil simulasi yang sesuai dengan data eksperimen. Nilai penyimpangan data terbesar diperoleh pada grafik $\mathrm{y} / \mathrm{b}=0.8$ sebesar 0.39. Plot grafik menunjukkan tekanan statis maksimum pada leading edge sesuai dengan tekanan stagnasi dan batas pemisah yang jelas antara daerah tekanan tinggi dan rendah yang terjadi akibat efek dari gelombang kejut.

\section{KeSIMPULAN}

Hasil simulasi CFD yang dilakukan memberikan kesimpulan bahwa hasil simulasi dengan menggunakan beberapa metode turbulensi memberikan hasil yang sesuai dengan data experiment dengan penyimpangan terbesar 0.39 diperoleh pada posisi $\mathrm{y} / \mathrm{b}=0.8$ [9].

\section{Daftar Pustaka}

[1] Anderson, J. D. 1995. “Computation Fluid Dynamic Basic With Application”. USA: John Wiley $\&$ Sons Inc.

[2] Fluent 6.3.26, 2006," Flow Modeling Software”. Fluent Inc

[3] Tuakia, F. 2008. "Dasar-Dasar CFD Menggunakan FLUENT”. Bandung: Informatika.

[4] https://www.grc.nasa.gov/WWW/wind/valid/m6wing/m6wing.html

[5] Fluent Theory Guide, 2006. Fluent, Inc.

[6] Spalart, P. R., Jou W-H., Strelets M., Allmaras, S. R., "Comments on the Feasibility of LES for Wings and on a Hybrid RANS/LES Approach" Advances in DNS/LES, 1st AFOSR Int. Conf. on DNS/LES, Greyden Press, Columbus Oh, 4-8 August, 1997

[7] Patel, R. and Ramani, S. 2015. "Determination of Optimum Domain Size for 3D Numerical Simulation in ANSYS CFX”. IJIRSET Vol. 4, Issue 6, June 2015

[8] Schmitt, V. and Charpin, F., "Pressure Distributions on the ONERA-M6-Wing at Transonic Mach Numbers," Experimental Data Base for Computer Program Assessment". Report of the Fluid Dynamics Panel Working Group 04, AGARD AR-138, May 1979

[9] Naveed Durrani and Ning Qin. Comparison of RANS, DES and DDES results for ONERA M-6 Wing at transonic flow speed using an in-house parallel code. 49th AIAA Aerospace Sciences Meeting including the New Horizons Forum and Aerospace Exposition 4 - 7 January 2011, Orlando, Florida. 